\title{
Clinical Trial Laboratory Sample Detail Documentation
}

National Cancer Institute

\section{Source}

National Cancer Institute. Clinical Trial Laboratory Sample Detail Documentation. NCI

Thesaurus. Code C115655.

Records pertaining to the collection, storage, shipping, tracking, location, and retention of a laboratory sample. 